Please do not remove this page

RMIT

UNIVERSITY

\title{
Modelling horizontal gas-liquid flow using averaged bubble number density approach
}

Li, Cong; Yeoh, G.H; Cheung, Chi Pok; Tu, Jiyuan

https://researchrepository.rmit.edu.au/esploro/outputs/9921857935501341/filesAndLinks?institution=61RMIT_INST\&index=null

Li, C., Yeoh, G. ., Cheung, C. P., \& Tu, J. (2010). Modelling horizontal gas-liquid flow using averaged bubble number density approach. Journal of Computational Multiphase Flows, 2(2), 89-99.

https://doi.org/10.3166/ria.24.291-346

Document Version: Published Version

Published Version: https://doi.org/10.3166/ria.24.291-346

Repository homepage: https://researchrepository.rmit.edu.au

(C) 2010 Multi-Science Publishing Co. Ltd.

Downloaded On 2023/04/27 01:23:05 +1000 
Thank you for downloading this document from the RMIT Research Repository.

The RMIT Research Repository is an open access database showcasing the research outputs of RMIT University researchers.

RMIT Research Repository: http://researchbank.rmit.edu.au/

\section{Citation: \\ Li, C, Yeoh, G, Cheung, C and Tu, J 2010, 'Modelling horizontal gas-liquid flow using averaged bubble number density approach', Journal of Computational Multiphase Flows, vol. 2, no. 2, pp. 89-99.}

See this record in the RMIT Research Repository at:

https://researchbank.rmit.edu.au/view/rmit:12676

Version: Published Version

Copyright Statement:

(C) 2010 Multi-Science Publishing Co. Ltd.

Link to Published Version: 


\title{
Modelling Horizontal Gas-Liquid Flow using Averaged Bubble Number Density Approach
}

\author{
C. Li', G. H. Yeoh ${ }^{2,3}$, S. C. P. Cheung ${ }^{1}$ and J. Y. Tu ${ }^{1}$ \\ ${ }^{1}$ School of Aerospace, Mechanical and Manufacturing Engineering \\ RMIT University, Victoria 3083, Australia \\ ${ }^{2}$ Australian Nuclear Science and Technology Organisation (ANSTO) \\ Locked Bag 2001 Kirrawee DC, NSW 2232, Australia \\ e-mail: guan.yeoh@ansto.gov.au \\ ${ }^{3}$ School of Mechanical and Manufacturing Engineering \\ University of New South Wales, Sydney 2052, Australia \\ e-mail: g.yeoh@unsw.edu.au
}

Received: 3 March 2010, Accepted: 30 June 2010

\begin{abstract}
In this study, the internal phase distributions of gas-liquid bubbly flow in a horizontal pipe have been predicted using the population balance model based on Average Bubble Number Density approach. Four flow conditions with average gas volume fraction ranging from $4.4 \%$ to $20 \%$ have been investigated. Predicted local radial distributions of void fraction, interfacial area concentration and gas velocity have been validated against the experimental data. In general, satisfactory agreements between predicted results and measured values have been achieved. For high superficial gas velocity, it has been ascertained that peak local void fraction of 0.7 with interfacial area concentration of $800 \mathrm{~m}^{-1}$ can be encountered near the top wall of the pipe. Some discrepancies have nonetheless been found between the numerical and experimental results at certain locations of the pipe. The insufficient resolution of the turbulent model in fully accommodating the strong turbulence in the current pipe orientation and the inclusion of additional interfacial force such as the prevalent bouncing force among bubbles remain some of the outstanding challenging issues need to be addressed in order to improve the prediction of horizontal gas-liquid bubbly flow.
\end{abstract}

Keywords: Multiphase flow model, porous media, heat transfer, multi-component mass transport, viscous force, fluid velocity

\section{INTRODUCTION}

Horizontal gas-liquid flow is commonly encountered in various industries because of its capability to provide large interfacial areas for heat and mass transfer in particular for the attachment of bitumen in hydro-transport phenomena. In such systems, air injection can be utilized to better improve bitumen produce efficiency. According to Malysa et al. (1999), by maintaining similar sizes, bitumen droplets have shown the tendency of attaching to the air bubbles. Furthermore, Luthra et al. (2003), Wallwork (2003) and Mankowski et al. (1999) have demonstrated that air injection can reduce energy assumption by helping bitumen recovery at lower process temperature $\left(<50^{\circ} \mathrm{C}\right)$. Since the size distribution of injected air bubbles can significantly influence bitumen processing system, the development of suitable modeling and simulation techniques capable of determining the size distribution in horizontal bubbly flow is indeed vital for the design and safe operation of bitumen hydro-transport system.

In retrospective, most studies of two-phase gas-liquid flows have been concerned with vertical configurations while horizontal gas-liquid flows have received considerably less attention. In 
vertical flows, buoyant force acts towards the same or opposite to the flow main direction. It balances with the drag force and mainly affects the gas-liquid relative velocity at the axial direction, but does not induce any lateral asymmetry in either the velocity or phase distribution. In horizontal flows, the buoyant force is nonetheless in the direction perpendicular to the flow main direction. It not only causes a significant flow asymmetry but also imposes an additional strong radial force. Thereby, under the combination of radial and axial forces, bubbles can travel neither vertically nor horizontally, which increases the difficulty in modeling horizontal gas-liquid flow in comparison to vertical gas-liquid flow.

Several measurement techniques have been utilized to describe the flow pattern in horizontal gas-liquid flow. Govier and Aziz (1972) have classified the flow patterns into five groups, namely bubbly, plug, slug, wave and annular (see Figure 1). Taitel and Dukler (1976) and Weisman et al. (1979) have mapped these flow regimes in a two-dimensional coordinate system and predicted their transition for numerous fluid properties and pipe sizes. Among all the flow regimes, bubbly flow is of the greatest interest because of their capability to provide large interfacial areas for industrial applications. Many researchers have focused on the prediction of internal structure of a horizontal bubbly flow. Some examples are: Kocamustafagullari and Wang (1991), (1994a), (1994b) and (1995), Andreussi et al. (1999), Iskandrani and Kojasoy (2001), Razzaque et al. (2003), Sanders et al. (2004) and Yang et al. (2004). Recently, interfacial structure of horizontal bubbly flow has been observed in 45-degree and 90-degree elbow by Kim et al. (2007) and (2009). For numerical studies, Haoues et al. (2009) and Talley and Kim (2010) have developed a drift flux model to predict the integral flow characteristics of horizontal bubbly flows. Teslishcheva et al. (2010). applied the two-fluid model to simulate the void fraction and velocity profiles in a long straight horizontal pipe and a similar pipe with a 90-degree elbow. The local spatial two-phase geometrical internal structure (bubble diameter or interfacial area concentration) in gas-liquid flows is affected by the coalescence and break-up through the interactions among bubbles as well as between bubbles and turbulent eddies in turbulent flows. In order to aptly predict the particle (bubble) size distribution, the population balance equation can be applied to handle the complicated bubble interaction mechanisms. Ekambara et al. (2008) have applied the MUltiple Size Group (MUSIG) model to investigate internal phase distribution of horizontal bubbly flow. In the MUSIG model, the continuous particle size distribution is discretized into series number of discrete size classes; the mass conversation of each size fractions are balanced by source terms which represent interfraction mass transfer due to the mechanisms of bubble coalescence and breakage processes. Computationally, as the number of transport equations depends on the number of group adopted, the MUSIG model generally requires large computational time and resources to achieve stable and accurate numerical predictions.

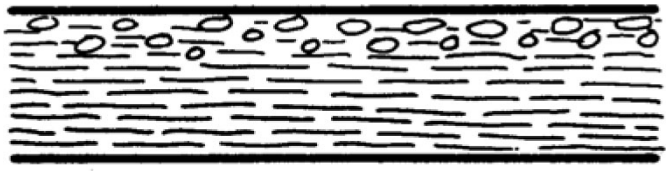

(a) Bubbly flow

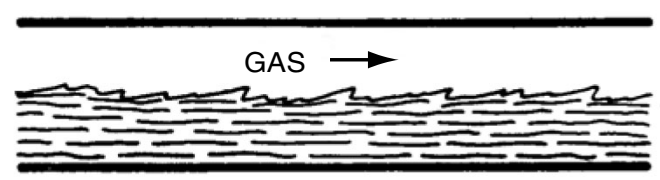

(c) Wave flow

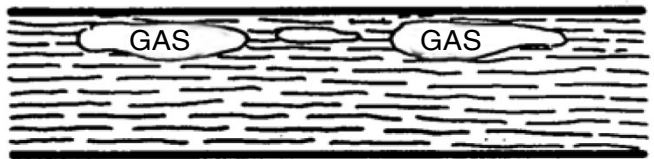

(b) Plug flow

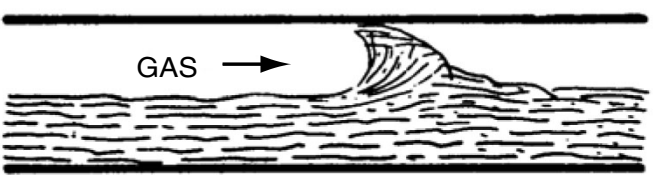

(d) Slug flow

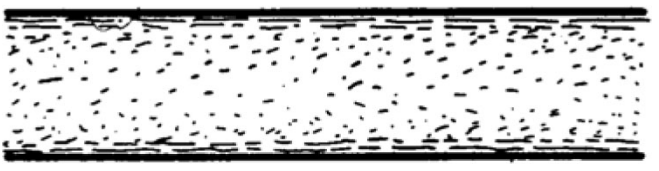

(e) Annular flow

Figure 1. Flow regimes for air-water flow in a horizontal pipe (Govier and Aziz, 1972). 
In the present of work, a simpler population balance model based on the Average Bubble Number Density approach is assessed in simulating the internal phase distributions of air-water bubbly flow in an inner diameter of $50.3 \mathrm{~mm}$ horizontal pipeline. Four flow conditions with average gas volume fraction from $4.4 \%$ to $20 \%$ were investigated. The predicted local radial distributions of void fraction, Interfacial Area Concentration (IAC) and gas velocity are compared against the experimental data of Kocamustafaogullari and Huang (1994a).

\section{MATHEMATICAL MODELS}

\subsection{Two-Fluid Model}

For isothermal bubbly flow without the heat and mass transfer, the three-dimensional two-fluid model conservation equations comprise the mass and momentum conservation equations. They are:

$$
\begin{gathered}
\frac{\partial\left(\rho_{i} \alpha_{i}\right)}{\partial t}+\nabla \cdot\left(\rho_{i} \alpha_{i} \vec{u}_{i}\right)=0 \\
\frac{\partial\left(\rho_{i} \alpha_{i} u_{i}\right)}{\partial t}+\nabla \cdot\left(\rho_{i} \alpha_{i} u_{i} u_{i}\right)=-\alpha_{i} \nabla P+\alpha_{i} \rho_{i} g+\nabla \cdot\left[\alpha_{i} \mu_{i}^{e}\left(\nabla u_{i}+\left(\nabla u_{i}\right)^{T}\right)\right]+F_{i}
\end{gathered}
$$

Relevant constitutive relationships for the interfacial forces, population balance model and suitable turbulent model are required to achieve closure of the two-fluid model equations, which are described below.

\subsection{Interfacial Forces}

In equation (2), $F_{i}$ represents the total interfacial forces calculated with averaged variables, which consist of the interfacial exchange between the liquid and bubble phases. Appropriate consideration of different sub-forces affecting the interaction between each phase can be formulated for isothermal bubbly flow as:

$$
F_{i}=F_{l \rightarrow g}=F_{l \rightarrow g}^{\mathrm{drag}}+F_{l \rightarrow g}^{\text {lift }}+F_{l \rightarrow g}^{\text {lubrication }}+F_{l \rightarrow g}^{\text {dispersion }}
$$

It should be noted that $F_{l \rightarrow g}$ in the above equation depicts the momentum transfer from the gas phase to the liquid phase. The sub-forces appearing on the right hand side of equation (3) are: drag, lift, wall lubrication and turbulent dispersion.

\section{Drag Force}

In the case of bubbly flow, the interfacial drag force is a result of the shear and form drag of the fluid flow which depends on the drag coefficient as well as the interfacial area concentration. It can be formulated according to

$$
F_{l \rightarrow g}^{\mathrm{drag}}=-F_{g \rightarrow l}^{\mathrm{drag}}=\frac{1}{8} C_{D} a_{i f} \rho_{l}\left|\vec{u}_{g}-\vec{u}_{l}\right|\left(\vec{u}_{g}-\vec{u}_{l}\right)
$$

where $C_{D}$ and $a_{i f}$ are the drag coefficient and interfacial area concentration, respectively. The Ishii and Zuber (1979) drag coefficients under consideration of different flow regimes are employed for gas-liquid flows. The coefficient $C_{D}$ can be correlated for individual bubbles across several distinct bubbles Reynolds number regions; Stoke, Undistorted Particle (viscous), Newton, Distorted Particle and Churn Turbulent Flow Regime.

\section{Lift Force}

Owing to radial velocity gradient, bubbles in a liquid are subjected to a lateral lift force. This interfacial force density can normally be correlated to the slip velocity and local vorticity of the continuous phase (curl of the velocity vector), which acts perpendicular to the direction of relative motion between two phases:

$$
F_{l \rightarrow g}^{\mathrm{lift}}=-F_{g \rightarrow l}^{\mathrm{lift}}=C_{L} \alpha_{g} \rho_{l}\left(u_{g}-u_{l}\right) \times\left(\nabla \times u_{l}\right)
$$


For the lift coefficient $C_{L}$ in above equation, Tomiyama (2004) correlations have been considered. It can be expressed as:

$$
C_{L}=\left\{\begin{array}{cl}
\min \left[0.288 \tanh \left(0.121 \mathrm{Re}_{g}\right) ; f\left(E o_{d g}\right)\right] & E o_{g}<4 \\
f\left(E o_{d g}\right)=0.00105 E o_{d g}^{3}-0.0159 E o_{d g}^{2}-0.0204 E o_{d g}+0.474 & 4 \leq E o_{g} \leq 10 \\
-0.29 & E o_{g}<4
\end{array}\right.
$$

where the modified Eotvos number $E o_{d g}$ is defined by

$$
E o_{d g}=\frac{g\left(\rho_{l}-\rho_{g}\right) d_{H}^{2}}{\sigma}
$$

in which $d_{H}$ is the maximum bubble radial dimension that can be evaluated through the correlation:

$$
d_{H}=D_{S}\left(1+0.163 E o_{g}^{0.757}\right)^{1 / 3}
$$

\section{Wall Lubrication Force}

In contrast to the lateral lift force, wall lubrication force constitutes another lateral force due to surface tension allowing bubble concentrated in a region close to the wall, but not immediately adjacent to the wall. This results in a low void fraction at the vicinity of the wall area. According to Antal et al. (1991) this force can be modelled as:

$$
F_{l \rightarrow g}^{\text {lubrication }}=-F_{g \rightarrow l}^{\text {lubrication }}=-\left(C_{w 1}+C_{w 2} \frac{D_{S}}{y_{w}}\right) \frac{\alpha_{g} \rho_{l}\left[\left(u_{g}-u_{l}\right)-\left(\left(u_{g}-u_{l}\right) \cdot n_{w}\right) n_{w}\right]^{2}}{D_{s}} n_{w}
$$

where $y_{w}$ is the distance to the nearest wall and $n_{w}$ is the unit normal pointing away from the wall. The wall lubrication constants determined through numerical experimentation for a spheres are $C_{w 1}=-0.01$ and $C_{w 2}=0.05$. Following a recent proposal by Krepper et al. (2005) the model constants have been modified according to $C_{w 1}=-0.0064$ and $C_{w 2}=0.016$. Moreover, for avoiding attraction force emerges, the force is set zero for large $y_{w:}$

$$
F_{1 \rightarrow \mathrm{g}}^{\text {lubrication }}=-F_{\mathrm{g} \rightarrow 1}^{\text {lubrication }}=0 \text { if } y_{w}>\frac{C_{w 2}}{C_{w 1}} D_{S}
$$

\section{Turbulent Dispersion Force}

Considering turbulent assisted bubble dispersion, turbulence dispersion force taken as a function of turbulent kinetic energy in the continuous phase and gradient of the volume fraction can be expressed in the form according to Antal et al. (1991) as:

$$
F_{l \rightarrow g}^{\text {dispersion }}=-F_{g \rightarrow l}^{\text {dispersion }}=-C_{T D} \rho_{l} k_{l} C_{D} \nabla \alpha_{l}
$$

where values of constant $C_{T D}$ ranging from 0.1 to 0.5 have been employed for bubbly flow with diameters of the order of millimetres. In some situations, values up to 500 have been required (Lopez de Bertodano, 1998, Moraga et al., 2003). Burns et al. (2004) have however derived an alternative model for the turbulence dispersion force based on the consistency of Favre-averaging, which is given by

$$
F_{l \rightarrow g}^{\text {dispersion }}=-F_{g \rightarrow l}^{\text {dispersion }}=C_{T D} C_{D} \frac{v_{t, g}}{\sigma_{t, g}}\left(\frac{\nabla \alpha_{l}}{\alpha_{l}}-\frac{\nabla \alpha_{g}}{\alpha_{g}}\right)
$$

where $C_{T D}$ is normally set to a value of unity, $v_{t, g}$ is the turbulent kinematic viscosity for the gas phase and $\sigma_{t, g}$ is the turbulent Schmidt number of the gas phase with an adopted value of 0.9. In 
equation (12), the constant $C_{D}$ depicts the drag coefficient which essentially describes the interfacial drag force. This model therefore clearly depends on the details of the drag characteristics of the gas-liquid systems. The more universal Favre-averaged turbulent dispersion force formulated in equation (12) is recommended for all situations where an appropriate value of $C_{T D}$ is unknown.

\subsection{Population Balance Model}

In order to represent bubble interaction mechanisms caused by the effects of coalescence and break-up through the interactions among bubbles as well as between bubbles and turbulent eddy in turbulent flows, the population balance model has been applied. In current study, an Average Bubble Number Density model recently proposed by Yeoh and Tu (2006) has been applied. The averaged bubble number density can be expressed as:

$$
\frac{\partial n}{\partial t}+\nabla \cdot\left(u_{g} n\right)=\phi_{n}^{R C}+\phi_{n}^{T I}+\phi_{n}^{W E}
$$

where $n=6 \alpha_{g} / \pi D_{s}{ }^{3}$ is the average bubble number density. The phenomenological mechanisms of coalescence and breakage are affected through the source and sink terms: $\phi_{n}^{R C}, \phi_{n}^{T I}$ and $\phi_{n}^{W E}$, of which they are due to random collision, turbulent induced breakage and wake entrainment. The Yao and Morel (2004) model is adopted in the present study, viz.,

$$
\begin{gathered}
\phi_{n}^{R C}=-C_{R C 1} \frac{\left(\alpha_{g}\right)^{2}\left(\varepsilon_{l}\right)^{1 / 3}}{D_{s}^{11 / 3}} \frac{\exp \left(-C_{R C 2} \sqrt{W e / W e_{c r}}\right)}{\left(\alpha_{\max }^{1 / 3}-\alpha^{d}\right) / \alpha_{\max }^{1 / 3}+C_{R C 3} \alpha^{d} \sqrt{W e / W e_{c r}}} \\
\phi_{n}^{T I}=C_{T I 1} \frac{\alpha_{g}\left(1-\alpha_{g}\right)\left(\varepsilon_{l}\right)^{1 / 3}}{D_{s}^{11 / 3}} \frac{\exp \left(-W e_{c r} / W e\right)}{1+C_{T I 2}\left(1-\alpha_{g}\right) \sqrt{W e / W e_{c r}}}
\end{gathered}
$$

where $C_{R C I}=2.86, C_{R C 2}=1.017, C_{R C 3}=1.922, C_{T I 1}=1.6$ and $C_{T I 2}=0.42$. The critical Weber number $W e_{c r}$ of 1.42 is employed (Sevik and Park, 1973). Considering the transition point from the finely dispersed bubbly flow to slug flow, the maximum allowable void fraction $\alpha_{\max }$ retains a value of 0.52 . According to Hibiki and Ishii (2002), wake entrainment phenomenon only plays significant influence in slug flow. In this study, wake entrainment has been ignored. More details regarding the model can be referred in Cheung et al. (2007a,b).

\subsection{Turbulence Modelling}

The Menter's (1994) Shear Stress Transport (SST) model that accounts for the transport of the turbulent shear stress for the liquid phase is employed in the present study. The SST model is a hybrid version of $k-\varepsilon$ and $k-\omega$ models with a specific blending function. It allows resolution of the flow explicitly down to the wall boundary instead of the use of empirical wall function to bridge the wall and the far-away turbulent flow. In handling bubble induced turbulent flow, the Sato's bubble-induced turbulent viscosity model (Sato et al. 1981) has been adopted to account for the effect of bubbles on the liquid turbulence.

\section{NUMERICAL DETAILS}

The numerical model is assessed against the experiments conducted by Kocamustafaogullari and Huang (1994a). Experiments for a range of superficial liquid velocities $\left\langle j_{f}\right\rangle$ and superficial gas velocities $\left\langle j_{g}\right\rangle$ at the location of $z / D=253$ have been performed. Table 1 summarizes the inlet boundary conditions for the various bubbly flows under consideration.

Solutions to the two sets of balance equations for mass and momentum of each phase is sought. An O-grid is generated for the cross-sectional plane of the long horizontal pipe such as illustrated in Figure 2. At the inlet of the test section, since the diameter of the injected bubbles are unknown, uniformly distributed superficial liquid and gas velocities, void fraction and bubble size are assumed in accordance with the flow conditions based on the inlet boundary conditions detailed in Table 1.

Volume $2 \cdot$ Number $2 \cdot 2010$ 
Table 1. Bubbly flow conditions and its inlet boundary conditions employed in the present study

\begin{tabular}{|c|c|c|c|c|}
\hline Superficial liquid velocity & & perficial gas & $\operatorname{city}\left\langle j_{g}\right\rangle(\mathrm{n}$ & \\
\hline $4.67 \mathrm{~m} / \mathrm{s}$ & $0.213 \mathrm{~m} / \mathrm{s}$ & $0.419 \mathrm{~m} / \mathrm{s}$ & $0.788 \mathrm{~m} / \mathrm{s}$ & $1.21 \mathrm{~m} / \mathrm{s}$ \\
\hline$\left[\left.\alpha_{g}\right|_{z / D=0.0}(\%)\right]$ & [4.4] & {$[8.5]$} & {$[14.6]$} & [20.46] \\
\hline$\left[\left.D_{S}\right|_{z / D=0.0}(\mathrm{~mm})\right]$ & {$[3.0]$} & {$[3.0]$} & {$[3.0]$} & {$[3.0]$} \\
\hline
\end{tabular}

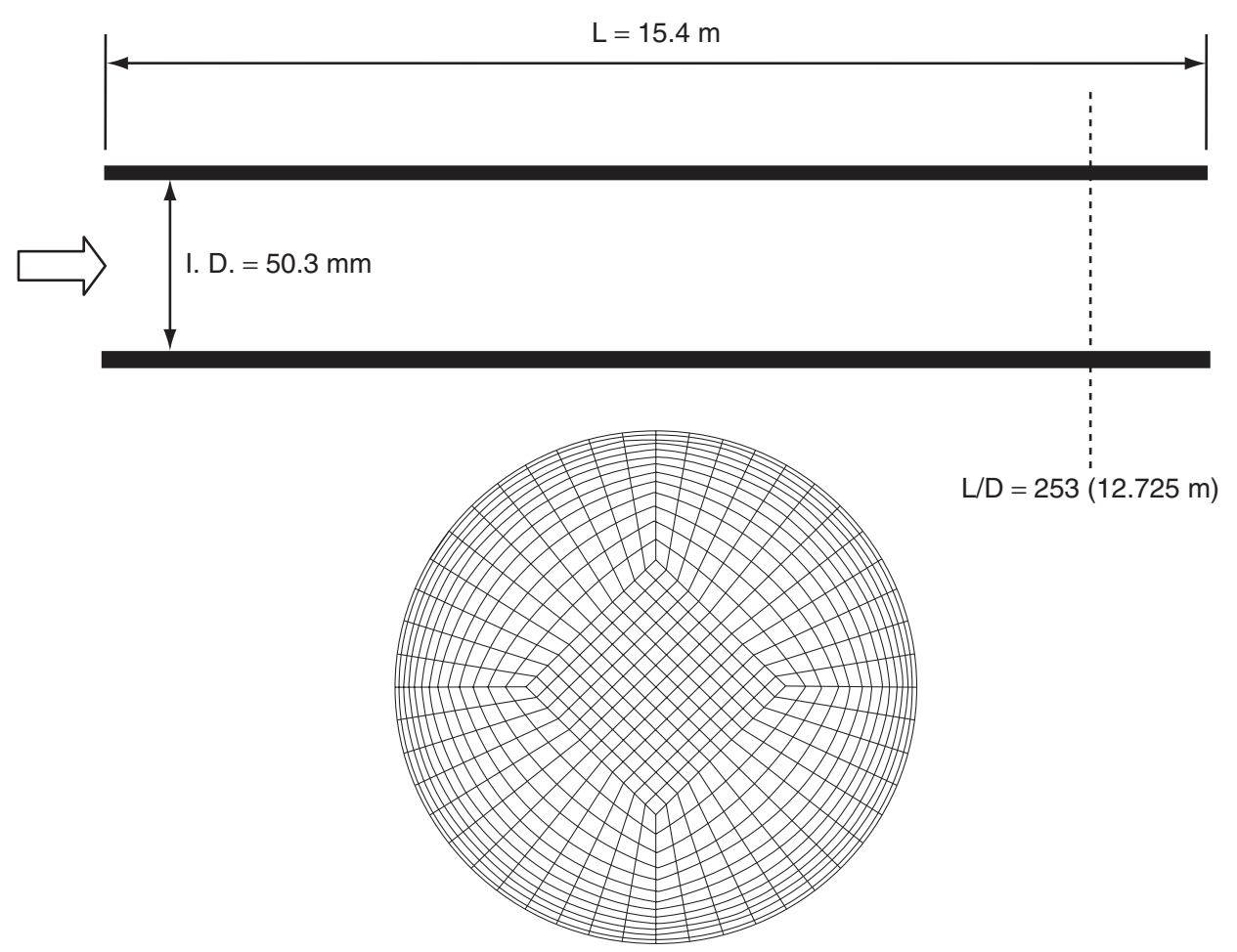

Figure 2. Schematic drawing of the test section and cross-sectional plane of the computational mesh for bubbly flow investigation in a long horizontal pipe.

\section{RESULTS AND DISCUSSIONS}

\subsection{Time Averaged Gas Void Fraction}

The predicted radial void fraction distribution of horizontal bubbly flow comparing against experimental data of Kocamustafaogullari and Huang (1994a) at the dimensionless axial position $z / D=253$ are shown in Figure 3. It can be seen from the gas void fraction profiles that a peak persisted in the vicinity of the upper wall of the pipe which was caused by the upward migration of gas bubbles due to the buoyant force balancing with a wall lubrication force being exerted downward to prevent the gas bubbles from collapsing at the upper wall. In contrast to vertical bubbly flow, the movement of bubble towards the wall is, in general, caused by the balance between the lift and wall lubrication forces. It can also be seen from the experiments that the peak gas void fraction value increased from the interfacial gas velocities from $\left\langle j_{g}\right\rangle=0.213 \mathrm{~m} / \mathrm{s}$ to $\left\langle j_{g}\right\rangle=0.789 \mathrm{~m} / \mathrm{s}$ to a level of 0.6 . At this level, this value has exceeded the maximum allowable void fraction of a value of 0.52 , which indicated that gas bubbles have reached the saturation limit 

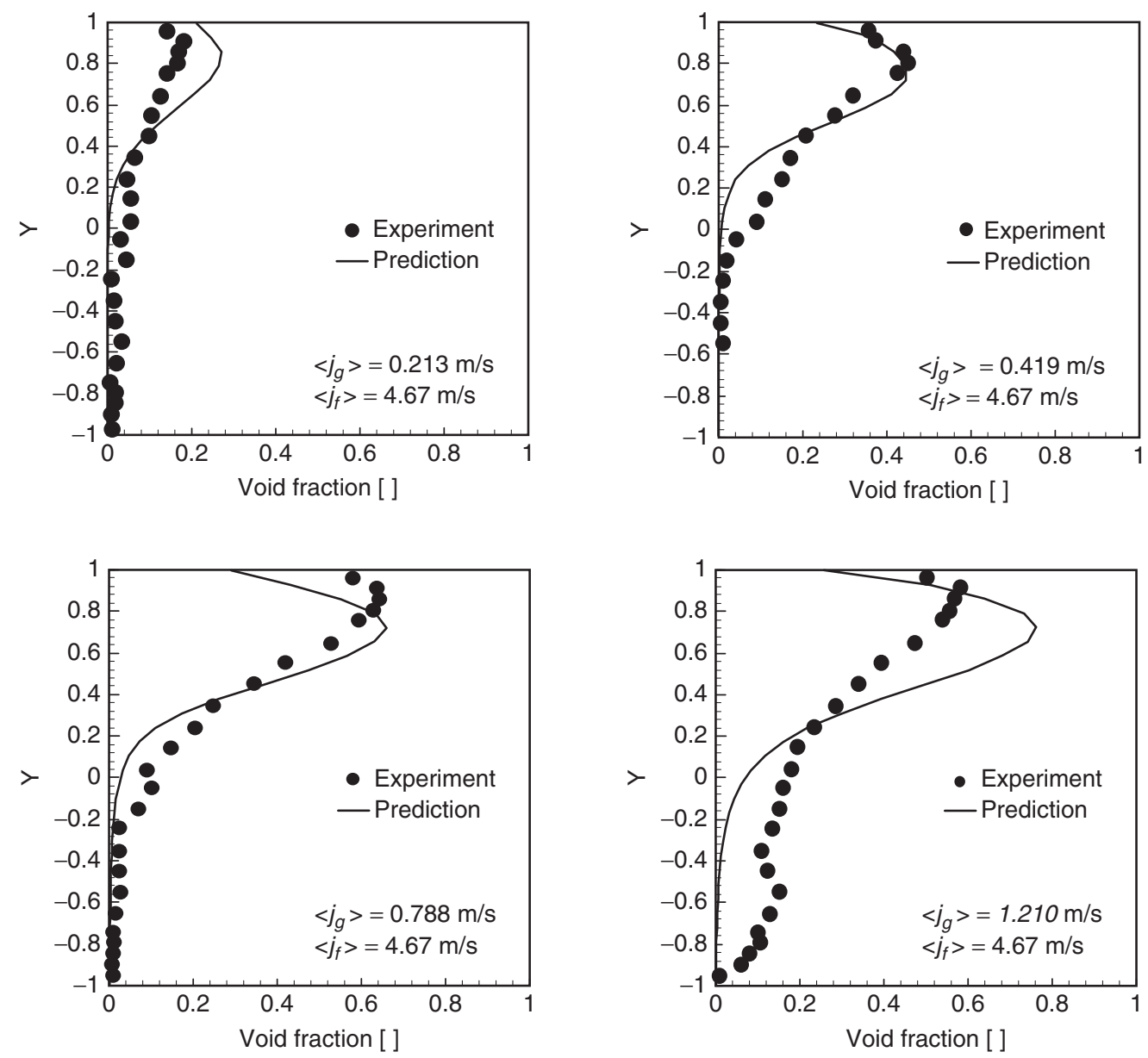

Figure 3. Predicted radial void fraction distributions and experimental data of Kocamustafaogullari and Huang (1994a) at location of L/D = 253.

at the upper wall. Further increasing the interfacial gas velocity to $\left\langle j_{g}\right\rangle=1.210 \mathrm{~m} / \mathrm{s} \mathrm{did} \mathrm{not} \mathrm{show}$ any appreciable increase of the peak gas void fraction in the vicinity of the upper wall. Rather, the local gas void fraction began to increase at the lower half of the pipe indicating the likelihood of gas bubbles migrating downwards.

Generally, the model predictions of the local gas void fraction are in good agreement with all the experimental conditions except for the interfacial gas velocity $\left\langle j_{g}\right\rangle=1.210 \mathrm{~m} / \mathrm{s}$. At this interfacial gas velocity, the model underestimated the local gas void fraction at the lower half of the pipe. One possible explanation could be the insufficiency of the turbulence-induced force to dramatically push the bubbles away from the pipe wall or the requirement to add a wall reaction force such as suggested by Tselishcheva et al. (2010) to counterbalance the buoyant force within horizontal bubbly flow. Nevertheless, the wall reaction force remains to be fully tested and deserves separate thorough investigation in the future.

\subsection{Time Averaged Interfacial Area Concentration (IAC)}

Figure 4 illustrates the predicted and measure Interfacial Area Concentration (IAC) corresponding to the of void fraction profile in Figure 3. With the assumption of spherically-shaped bubbles, the IAC can be simply calculated by local void fraction $\alpha_{\mathrm{g}}$ and Sauter mean diameter $D_{s}$ through:

$$
a_{i f}=\frac{6 \alpha_{g}}{D_{s}}
$$



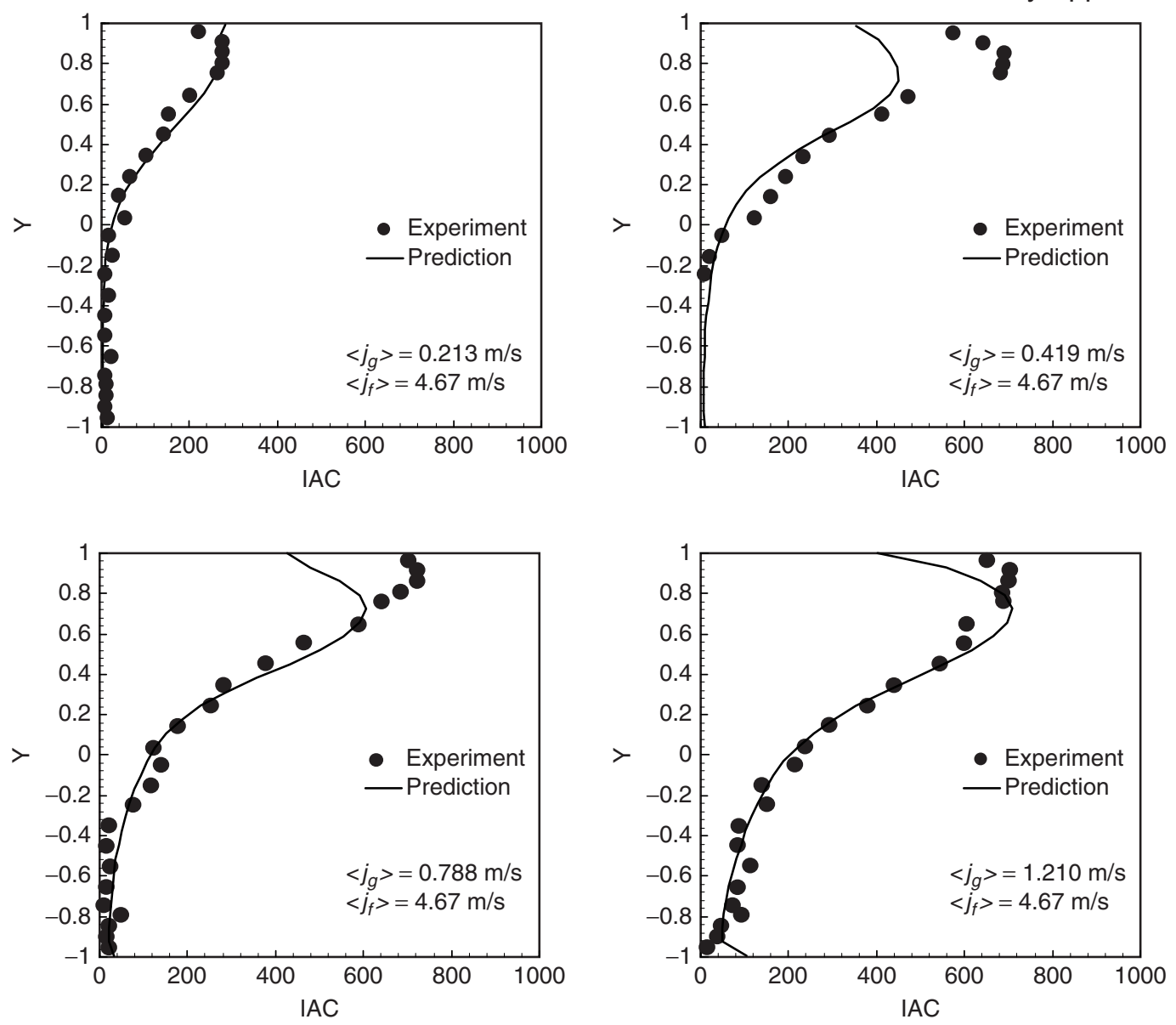

Figure 4. Predicted radial IAC distributions and experimental data of Kocamustafaogullari and Huang (1994a) at location of L/D = 253.

As observed in Kocamustafaogullari and Huang (1994a), the Sauter mean bubble diameter distribution was nearly uniform for any given flow condition. It is therefore not surprising that the IAC followed very closely to the void fraction distributions.

As shown in Figure 4, the model yielded reasonable prediction comparing with experimental data except for the underestimation of IAC peak at the vicinity of the wall for the interfacial gas velocities of $\left\langle j_{g}\right\rangle=0.419 \mathrm{~m} / \mathrm{s}$ and $\left\langle j_{g}\right\rangle=0.788 \mathrm{~m} / \mathrm{s}$. This was probably due to the lack of robustness of the model constants adopted in the Yao and Morel (2004) model which required calibration in order to aptly predict the bubble size within the isothermal bubbly flow for these conditions. Owing to the larger Sauter mean diameter, lower than expected IAC was subsequently attained.

\subsection{Time Averaged Liquid Velocity}

Figure 5 shows the comparison of predicted and experimental data of axial components of liquid mean velocity profiles for various interfacial gas velocities under the fixed superficial liquid velocity of $\left\langle j_{f}\right\rangle=4.67 \mathrm{~m} / \mathrm{s}$. The experimental data demonstrated that changes in the velocity profile shape are very small compared with the changes in the void fraction and IAC. There are no peaks in gas velocity profile corresponding to those observed toward the top wall peaking in void fraction and IAC.

As suggested by Beattie (1972), there is no evidence to suggest a strong proportionate correspondence between void fraction and velocity profiles. Similar phenomena have also been observed in vertical bubbly flow. For example in Hibiki and Ishii (2001), the "wall peak" void fraction profile has no influence on velocity distribution. 

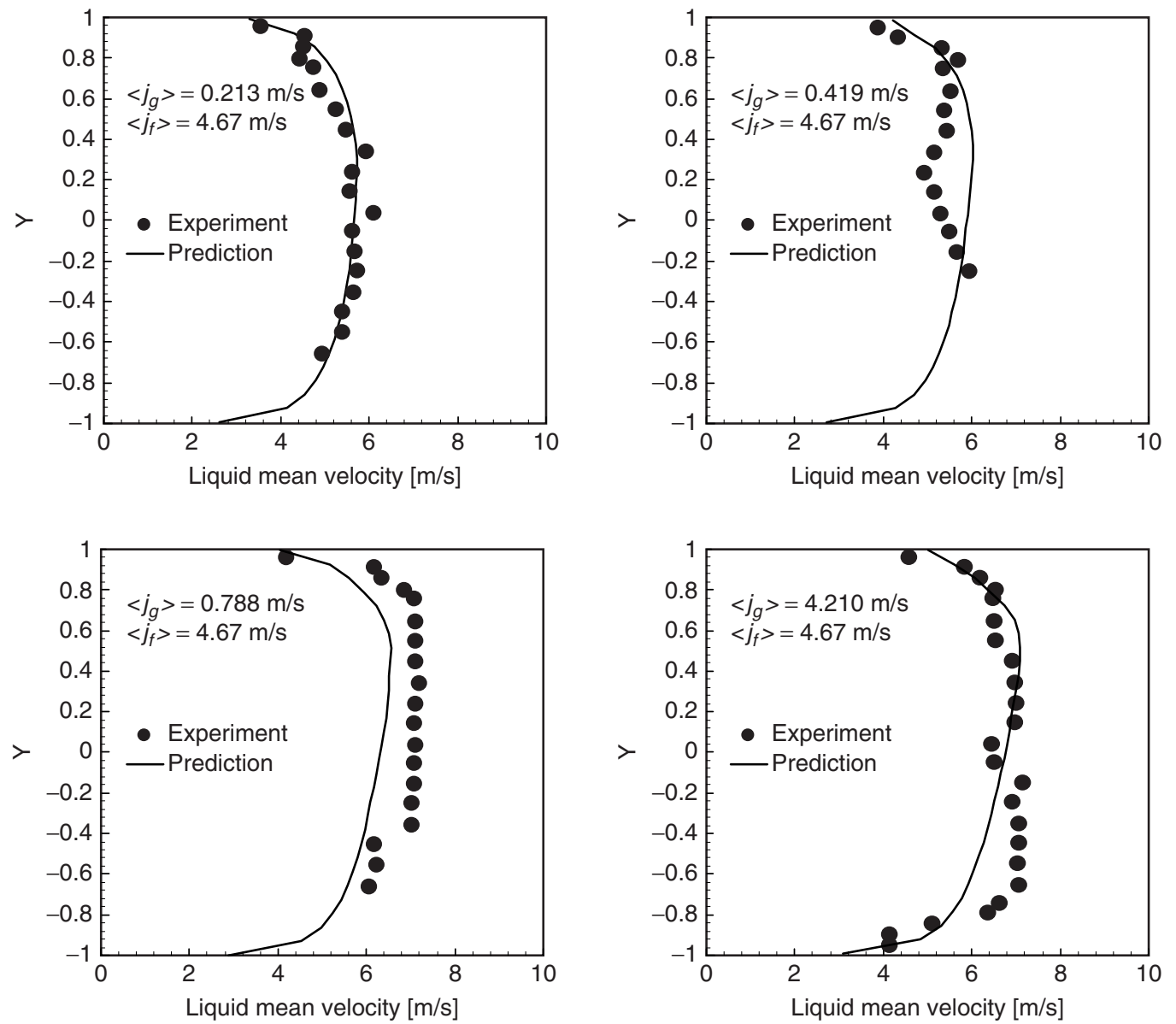

Figure 5. Predicted radial liquid mean velocity and experimental data of Kocamustafaogullari and Huang (1994a) at location of $L / D=253$.

In vertical bubbly flow condition, bubble accelerates along axial direction driving by the strong buoyant force, gas bubbles therefore rises faster than liquid while liquid velocities in gas-liquid flow system are greater than ones in single phase flow system under the same flow conditions due to the inertial force between gas and liquid. However, in horizontal bubbly flow condition, the buoyant force which is normal to flow axial direction have a lesser contribution in pushing the gas bubble to move along axial direction than that in vertical bubbly flow. According to Kocamustafaogullari and Huang (1994a) liquid velocities are slightly greater than the bubble velocities and the bubbles are accelerated by liquid inertia in a very short distance after injection and the local gas phase velocities closely follow closely the local liquid phase velocities. As seen in Figure 5, the numerical results are in reasonable prediction with the experimental data.

\section{CONCLUSIONS}

In this study, the internal phase distributions of air-water bubbly flow in an inner diameter of $50.3 \mathrm{~mm}$ horizontal pipeline have been investigated using the two-fluid and ABND models. The predicted local radial distributions of void fraction, IAC and liquid mean velocity have been validated against the experimental data of Kocamustafaogullari and Huang (1994a).

In general, satisfactory agreements between predicted and measured results were achieved. The results indicated that the local gas void fraction and IAC peaked near the upper pipe wall because of the buoyant effect. The liquid mean velocity profiles corresponded to fully-developed turbulent pipe-flow profiles, which meant highly non-symmetric void fraction has less of an influence on the liquid velocity distribution. Some discrepancies were found between the numerical and 
experimental results. Better turbulent model to capture the physical processes associated with complex turbulent bubbly flow in horizontal pipe or additional interfacial force such as bouncing force among bubbles may need to be considered to further improve the model predictions.

\section{REFERENCES}

Andreussi, P., A. Paglianti, et al. (1999). Dispersed bubble flow in horizontal pipes. Chem. Eng. Sci., 54, 1101-1107.

Antal, S. P., R. T. Lahey, et al. (1991). Analysis of phase distribution in fully-developed laminar bubbly 2-phase flow. Int. J. Multiphase Flow, 17, 635-652.

Beattie, D. R. H. (1972). 2-phase flow structure and mixing length, Nuc. Eng. Des., 21, 46-64.

Burns, A. D., Frank, T., Hamill, I., Shi, J. (2004). The Favre averaged drag model for turbulent dispersion in Eulerian multiphase flow. Proceedings of the Fifth International Multiphase Flow, Yokohama, Japan.

Cheung, S. C. P., Yeoh, G. H., Tu, J. Y. (2007a). On the numerical study of isothermal vertical bubbly flow using two population balance approaches. Chem. Eng. Sci., 62, 4659-4674.

Cheung, S. C. P., Yeoh, G. H., Tu, J. Y. (2007b). On the modelling of population balance in isothermal vertical bubbly flows - Average bubble number density approach. Chem. Eng. Process., 46, 742-756.

Ekambara, K., Sanders, R. S., Nandakumar, K., Masliyah, J. H. (2008). CFD simulation of bubbly two-phase flow in horizontal pipes. Chem. Eng. J., 144, 277-288.

Haoues, L., Olekhnovitch, A., Teyssedou, A. (2009). Numerical study of the influence of the internal structure of a horizontal bubbly flow on the average void fraction. Nuc. Eng. Des., 239, 147-157.

Hibiki, T., Ishii, M. (2000). One-group interfacial area transport of bubbly flows in vertical round tubes. Int. J. Heat Mass Transfer, 43, 2711-2726.

Hibiki, T., Ishii, M. (2001). Axial interfacial area transport of vertical bubbly flows. Int. J. Heat Mass Transfer, 44, $1869-1888$.

Ishii, M., Zuber, N. (1979). "Drag coefficient and relative velocity in bubby, droplet or particulate flows. AIChE J., 25, $843-855$.

Iskandrani, A., Kojasoy, G. (2001). Local void fraction and velocity field description in horizontal bubbly flow. Nuc. Eng. Des., 204, 117-128.

Kim, S., Callender, K., Kojasoy, G. (2009). Interfacial area transport in horizontal bubbly flow with 90-degree elbow. Nuc. Tech., 167, 20-28.

Kim, S., Park, J. H., Kojaosy, G., Kelly, J. M., Marshall, S. O. (2007). Geometric effects of 90-degree Elbow in the development of interfacial structures in horizontal bubbly flow. Nuc. Eng. Des., 237, 2105-2113.

Kocamustafaogullari, G. Huang, W. D. (1994a). "Internal structure and interfacial velocity development for bubbly 2-phase flow. Nucl. Eng. Des., 151, 79-101.

Kocamustafaogullari, G., Huang, W. D., Razi, J. (1994b). Measurement and modeling of average void fraction, bubble size and interfacial area. Nuc. Eng. Des., 148, 437-453.

Kocamustafaogullari, G., Ishii, M. (1995). Foundation of the interfacial area transport equation and its closure relations. Int. J. Heat Mass Transfer, 38, 481-493.

Kocamustafaogullari, G., Wang, Z. (1991). "An experimental study on local interfacial parameters in a horizontal bubbly 2-phase flow. Int. J. Multiphase Flow, 17, 553-572.

Krepper, E., Lucas, D., Prasser, H.-M. (2005). On the modelling of bubbly flow in vertical pipes. Nuc. Eng. Des. 235 , 597-611.

Lopez de Bertodano, M. (1998). Two-fluid model for two-phase turbulent jet, Nuc. Eng. Des., 179, 65-74.

Luthra, M., Lopetinsky, R. J. G., Sanders, R. S., Nandakumar, K., Masliyah, J. H. (2003). A new device to determine oil sands processability under hydrotransport conditions, Can. J. Chem. Eng., 82, 752-762.

Malysa, K., Ng, S., Cymbalisty, L., Czarnecki, J., Masliyah, J. (1999). A method of visualization and characterization of aggregate flow inside a separation vessel, Part 1. Size, shape and rise velocity of the aggregates. Int. J. Mineral Process., 55, 171-188.

Menter, F. R. (1994). 2-equation eddy-viscosity turbulence models for engineering applications. AIAA J., 32, 1598-1605.

Mankowski, P., Ng, S., Siy, R., Spence, J., Stapleton, P. (1999). Syncrude's low energy extraction process: commercial implementation. Proceeding of 31st Annual Meeting of Canada Mineral Processing, Ottawa, 153-181.

Moraga, F. J., Larreteguy, A. E., Drew, D. A., Lahey, R. T. Jr. (2003). Assessment of turbulent dispersion models for bubbly flows in the low Stokes number Limit, Int. J. Multiphase Flow, 29, 655-673. 
Razzaque, M. M., Afacan, A., Liu, S., Nandakumar, K., Masliyah J. H., Sanders, R. S. (2003). Bubble size in coalescence dominant regime of turbulent air-water flow through horizontal pipes. Int. J. Multiphase Flow, 29, 1451-1471.

Sanders, R. S., Razzaque, M. M., Schaan, J., Nandakumar, K., Masliyah, J. H., Afacan, A., Shijie, L. (2004). Bubble size distributions for dispersed air - Water flows in a $100 \mathrm{~mm}$ horizontal pipeline. Can. J. Chem. Eng., 82, 858-864.

Sato, Y., Sadatomi, M., Sekoguchi, K. (1981). Momentum and heat transfer in 2-phase bubble flow. 1. Theory. Int. J. Multiphase Flow, 7, 167-177.

Taitel, Y., Dukler, A. E. (1976). Model for predicting flow regime transitions in horizontal and near horizontal gas-liquid flow. AIChE J., 22, 47-55.

Talley, J. D., Kim, S. (2010). Horizontal bubbly flow with elbow restrictions: Interfacial area transport modeling. Nuc. Eng. Des., 240, 1111-1120.

Tomiyama, A. (2004). Drag, lift and virtual mass forces acting on a single bubble. 3rd International Symposium on Twophase Flow Modelling and Experimentation, Pisa, 22-24.

Tselishcheva, E. A., Antal, S. P., Podowski, M. (2010). "Mechanistic multidimensional analysis of horizontal two-phase flows". Nuc. Engi. Des., 240, 405-415.

Weisman, J., Duncan, D., Gibson, J., Crawford, T. (1979). Effects of fluid properties and pipe diameter on 2-phase flow patterns in horizontal lines. Int. J. Multiphase Flow, 5, 437-462.

Yang, J., Zhang, M. Y., Su, Y., Zhang, C. (2004). "Quasi 3-D measurements of turbulence structure in horizontal air-water bubbly flow". Nuc. Eng. Des., 227, 301-312.

Yao, W., Morel, C. (2004). Volumetric interfacial area prediction in upward bubbly two-phase flow. Int. J. Heat Mass Transfer, 47, 307-328.

Yeoh, G. H., Tu, J. Y. (2006). Numerical modelling of bubbly flows with and without heat and mass transfer. Appl. Math. Model., 30, 1067-1095.

Wallwork, V., (2003). An Investigation of Oil Sand Processability, M. Sc. Thesis, University of Alberta, Edmonton. 